Article

\title{
Carbon Nanotube Field Emitters Synthesized on Metal Alloy Substrate by PECVD for Customized Compact Field Emission Devices to Be Used in X-Ray Source Applications
}

\author{
Sangjun Park ${ }^{1,+}{ }^{+}$Amar Prasad Gupta ${ }^{1,2,+}$ (D) , Seung Jun Yeo ${ }^{1,2}$, Jaeik Jung ${ }^{2}$, Sang Hyun Paik ${ }^{2,3}$, \\ Mallory Mativenga ${ }^{4}$, Seung Hoon Kim ${ }^{5}$, Ji Hoon Shin ${ }^{5}$, Jeung Sun Ahn ${ }^{1, *}$ and \\ Jehwang Ryu 1,2,* (iD) \\ 1 Department of Physics, Kyung Hee University, Seoul 02453, Korea; sjpark1112@khu.ac.kr (S.P.); \\ amargupta@khu.ac.kr (A.P.G.); sjyeo@khu.ac.kr (S.J.Y.) \\ 2 CAT Beam Tech Co., Ltd., Seoul Biohub, 117-3, Hoegi-ro, Dongdaemun-gu, Seoul 02455, Korea; \\ jijung@catbeamtech.com (J.J.); radpsh@gmail.com (S.H.P.) \\ 3 Department of Radiology, Vinmec International Hospital, Ha Noi 10000, Vietnam \\ 4 Department of Information Display, Kyung Hee University, Seoul 02453, Korea; mallory@khu.ac.kr \\ 5 Department of Radiology, Asan Medical Center, University of Ulsan College of Medicine, \\ Seoul 05505, Korea; kimsh6713@gmail.com (S.H.K.); jhshin@amc.seoul.kr (J.H.S.) \\ * Correspondence: johnsonahn@khu.ac.kr (J.S.A.); jhryu@khu.ac.kr (J.R.); Tel.: + 82-2-959-2016 (J.R.) \\ + These authors contributed equally to this work.
}

Received: 18 April 2018; Accepted: 24 May 2018; Published: 29 May 2018

\begin{abstract}
In this study, a simple, efficient, and economical process is reported for the direct synthesis of carbon nanotube (CNT) field emitters on metal alloy. Given that CNT field emitters can be customized with ease for compact and cold field emission devices, they are promising replacements for thermionic emitters in widely accessible X-ray source electron guns. High performance CNT emitter samples were prepared in optimized plasma conditions through the plasma-enhanced chemical vapor deposition (PECVD) process and subsequently characterized by using a scanning electron microscope, tunneling electron microscope, and Raman spectroscopy. For the cathode current, field emission (FE) characteristics with respective turn on $\left(1 \mu \mathrm{A} / \mathrm{cm}^{2}\right)$ and threshold $\left(1 \mathrm{~mA} / \mathrm{cm}^{2}\right)$ field of 2.84 and $4.05 \mathrm{~V} / \mu \mathrm{m}$ were obtained. For a field of $5.24 \mathrm{~V} / \mu \mathrm{m}$, maximum current density of $7 \mathrm{~mA} / \mathrm{cm}^{2}$ was achieved and a field enhancement factor $\beta$ of 2838 was calculated. In addition, the CNT emitters sustained a current density of $6.7 \mathrm{~mA} / \mathrm{cm}^{2}$ for $420 \mathrm{~min}$ under a field of $5.2 \mathrm{~V} / \mu \mathrm{m}$, confirming good operational stability. Finally, an X-ray generated image of an integrated circuit was taken using the compact field emission device developed herein.
\end{abstract}

Keywords: carbon nanotubes; PECVD; metal alloy; field emission; compact field emission device; X-ray source

\section{Introduction}

Due to their strong $\mathrm{C}-\mathrm{C}$ covalent bonds and high aspect ratio [1], carbon nanotubes (CNTs) exhibit extraordinary properties, such as high thermal conductivity, good chemical stability, and high mechanical strength. These properties make developing CNTs as cold field emitters very appealing for $\mathrm{X}$-ray, microwave, and field emission display applications [2-4].

The CNT field emitter is commonly grown on a rigid semiconducting and insulating substrate, such as silicon or glass, to facilitate the formation of uniform nanoscale catalyst particles necessary 
for the assisted-growth of CNTs [5]. However, due to the relatively low electrical conductivity of the interface between the CNT emitter and aforementioned substrates, emitters grown in such manner have high turn on and unstable field emission [6]. Li et al. synthesized CNTs on a metal alloy substrate by coating its surface with $\mathrm{Ni}$ before synthesis. Given that catalyst seeds, such as $\mathrm{Ni}, \mathrm{Cr}, \mathrm{Fe}, \mathrm{Co}$, and $\mathrm{Mo}$, are needed for the nucleation of CNTs, many reports emphasize the direct growth of CNTs on metal alloy substrates such as alloys of $\mathrm{Ni}, \mathrm{Fe}$, and the $\mathrm{Cr}$ (NFC alloy) system [7-11]. By using these metal alloy substrates (with or without surface modification), separate processes involving the sputtering of the above mentioned active catalysts and/or reagents, such as $\mathrm{HNO}_{3}$ and $\mathrm{HCl}$, can be avoided. This ultimately makes the process much simpler and economical. Moreover, epitaxial growth of CNTs on NFC alloy yields superior intrinsic qualities, such as high electrical conductivity and mechanical properties [7], making NFC alloy the best substrate choice for direct synthesis of CNTs.

We have recently proposed a simpler and economical way to directly synthesize CNT emitters on a metal alloy substrate (type of alloy: Hitachi Metal Corp., Tokyo, Japan, YEF 426, Ni-42\%, Fe-52\%, Cr-6\%) with sufficient field emission for a custom built, open type X-ray system that can be used for biomedical applications [12]. The application of cold cathode emitters in X-ray source systems has gained much attention because of digitalized active control switching and relatively lower radiation emission compared to traditional thermionic emitters [13]. Although Si nanorods [14], $\mathrm{ZnO}$ nanorods [15], Mo [16], $\mathrm{MoS}_{2}$ [17], diamond films [18], graphene [19] etc. could be used as cold cathode emitters, none of them have proven to be as efficient as CNT-based emitters. Recently, FDA has approved the commercialization of a CNT emitter-based X-ray machine, developed by O. Zhou et al. [20]. Irrespective of the types of the cold cathode emitter, the prime focus in the development of both sealed or open-type X-ray source systems is the assembly of the field emission device in the electron gun. A small and compact field emission device is crucial to the development of portable, cheap, and small-sized X-ray source systems. In addition, a compact field emission device will highly facilitate multi-X-ray source systems that can be employed in novel imaging systems such as computed tomography, 3D Breast Tomosynthesis, etc. [21]. Although different types of compact field emission devices have been reported [22], none of them are sustainable nor utilize the conventional electron gun which is widely available in the market.

Towards the development of simple and economical CNT field emitters for X-ray source applications, we have optimized the plasma condition inside the PECVD chamber to grow high performance CNT emitters on a metal alloy substrate, without any pre-processing, sputtering of catalyst nor reduction with reagents. The CNT emitters are custom developed for the assembly of a compact field emission device that can replace thermionic emitters in conventional electron guns, and can play a significant role in the development of multi X-ray source systems.

\section{Materials and Methods}

Ellipsoid shape metal alloy substrates having thickness of $100 \mu \mathrm{m}$ and emission area of $0.1377 \mathrm{~cm}^{2}$ with composition of $\mathrm{Ni} 42 \%, \mathrm{Cr} 6 \%$, and Fe 52\%, were chosen for the synthesis of CNTs by a custom built diode PECVD process. Prior to growing, a basic cleaning procedure was performed in ultrasonic bath using acetone and followed by isopropyl alcohol (IPA). Each of the cleaning procedures took $10 \mathrm{~min}$. After cleaning, the substrates were placed on a steel substrate holder, which was placed above a ceramic holder surrounding a graphite heater. The distance between two electrodes (substrate and mesh) was $10 \mathrm{~mm}$, heater temperature was set at $900{ }^{\circ} \mathrm{C}$, and base pressure of the chamber was maintained at $3.5 \times 10^{-6}$ Torr. The graphite heater was heated at $20^{\circ} \mathrm{C} / \mathrm{min}$. The anode voltage was supplied by EX-375 (Takasago LTD, Tokyo, Japan), whereas the cathode voltage was supplied by PWR400M (Kikusui Electronics Corp., Kanagawa, Japan). Growing procedures were performed in 3 steps, namely pre-treatment, growth, and post-treatment. During all these steps, the temperature of the reactor was maintained at $900{ }^{\circ} \mathrm{C}$. In $\mathrm{NH}_{3}$ atmosphere, pre-treatment pressure was 4.2 Torr and the applied voltage between the two electrodes was $500 \mathrm{~V}$. The $500 \mathrm{~V}$ DC is the optimum voltage required to form a plasma sheath right above the susceptor. The value was determined experimentally. 
The pre-treatment was carried out for $10 \mathrm{~min}$ and to form the nucleation sites for CNT growth on the surface of the metal substrates. Nucleation sites were formed due to etching of the substrate by $\mathrm{NH}_{3}$ plasma [23]. It has been reported before that the pre-treatment with $\mathrm{NH}_{3}$ plasma forms better nucleation sites compared to pre-treatment with $\mathrm{NH}_{3}$ gas [24]. Subsequently, $\mathrm{NH}_{3}$ and $\mathrm{C}_{2} \mathrm{H}_{2}$ were respectively inserted together to synthesize CNTs at 70 and $30 \mathrm{sccm}$ for $30 \mathrm{~min}$. During the growth process, pressure was maintained at 5 Torr. The post-treatment involved the annealing of CNTs under $\mathrm{NH}_{3}$ plasma for $1 \mathrm{~min}$ at $900{ }^{\circ} \mathrm{C}$ followed by natural cooling. The decreasing ratio of acetylene to ammonia during post-treatment helps to remove the unwanted amorphous carbon and nanoparticles on CNT. This improves the crystallinity of the graphitic surface and field emission characteristics $[25,26]$. Figure 1 shows both the optical image and schematic diagram of optimized plasma formation, during the PECVD growth process. We found that, in the PECVD process, plasma profile control is key to the proper synthesis of CNTs on metal substrates. Many studies have been reported on the optimization of the plasma profile through voltage bias, heater temperature, gas flow, and pressure $[5,8]$. In the present study, we optimized the plasma profile by controlling the anode voltage and pressure in a way that the plasma sheath is formed right above the susceptor.

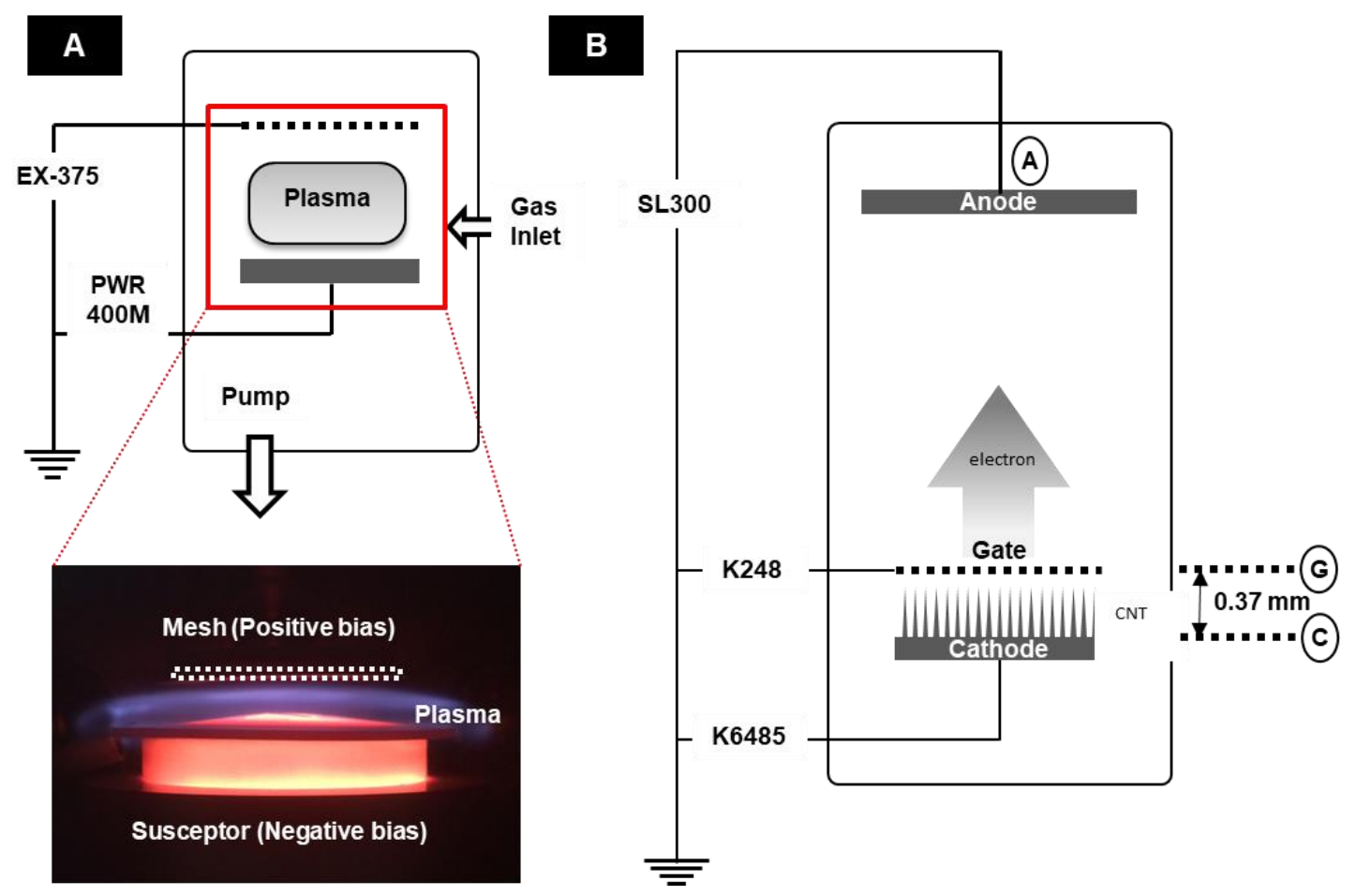

Figure 1. (A) Optical image and schematic diagram of plasma-enhanced chemical vapor deposition (PECVD); (B) Schematic diagram of field emission (FE).

Scanning electron microscopy (SEM, Hitachi SU-70, Hitachi High-Technologies Corporation, Tokyo, Japan) was utilized to analyze the morphology of the CNT forest. Tunneling electron microscopy (TEM, Titan 80-300, FEI Company, Hillsboro, OR, USA) was used to analyze single and multi-walled CNTs (MWCNTs) and Raman spectroscopy (Jobin-Yvon T64000, Horiba Scientific Longjumeau, France) with $515 \mathrm{~nm}$ laser was used to characterize the crystallinity of CNTs.

The field emission (FE) measurement was done at a base pressure of $10^{-7}$ Torr in triode condition. Figure 1B describes the set-up of the FE experiment. The Keithley 6485 (Keithley Instruments, Inc., Cleveland, OH, USA) was chosen to measure the cathode current, whereas the Keithley 248 (Keithley Instruments, Inc., Cleveland, OH, USA) was selected for measuring the gate current and as the gate voltage source. The Spellman SL300 (Spellman High Voltage Electronics Corporation, New York, NY, USA) was applied to measure the anode current and as the anode voltage source. Anode voltages of all FE 
measurements were obtained below $8 \mathrm{kV}$ in pulsed mode with $1 \mathrm{kHz}$ frequency and $50 \%$ duty cycle. The turn-on field and threshold field were defined as the gate fields corresponding to current densities of $1 \mu \mathrm{A} / \mathrm{cm}^{2}$ and $1 \mathrm{~mA} / \mathrm{cm}^{2}$, respectively. For the FE measurement and X-ray image acquisition, the as-grown CNT emitters were assembled into a compact field emission device and then placed into a conventional electron gun as a cathode for the open-type X-ray system, which had been reported in detail elsewhere [12]. Figure 2A illustrates the 3D diagram of the compact field emission device used herein. It consists of a metal mesh that is made up of Kovar and with regular hexagonal sides of $360 \mu \mathrm{m}$, an area of $0.00336 \mathrm{~cm}^{2}$, and aperture ratio of $89.7 \%$. The CNT emitters inside the compact field emission device were fixed at a distance of $370 \mu \mathrm{m}$ from the mesh electrode. Figure $2 \mathrm{~B}$ shows the optical image of the compact field emission device and filament-removed, dual-type conventional electron gun, which also signifies the compactness of the electron gun assembly. The absence of focuser in the compact field emission device has been compensated by the focusing structure (inside the red dashed-line rectangle) of the conventional electron gun. Given that the compact field emission device weighs around $0.3 \mathrm{~g}$ (Figure 2C), light-weight is one of its strong attributes. The distance between the emitter and anode was maintained at $2 \mathrm{~cm}$ during the FE measurement. For X-ray image acquisition, an integrated circuit board was used. The detector (RAD icon 0889, Teledyne Rad-icon Imaging Corp., CA, USA) with $1024 \times 512$ pixels was placed $25 \mathrm{~cm}$ away from the X-ray system to take high-resolution images.
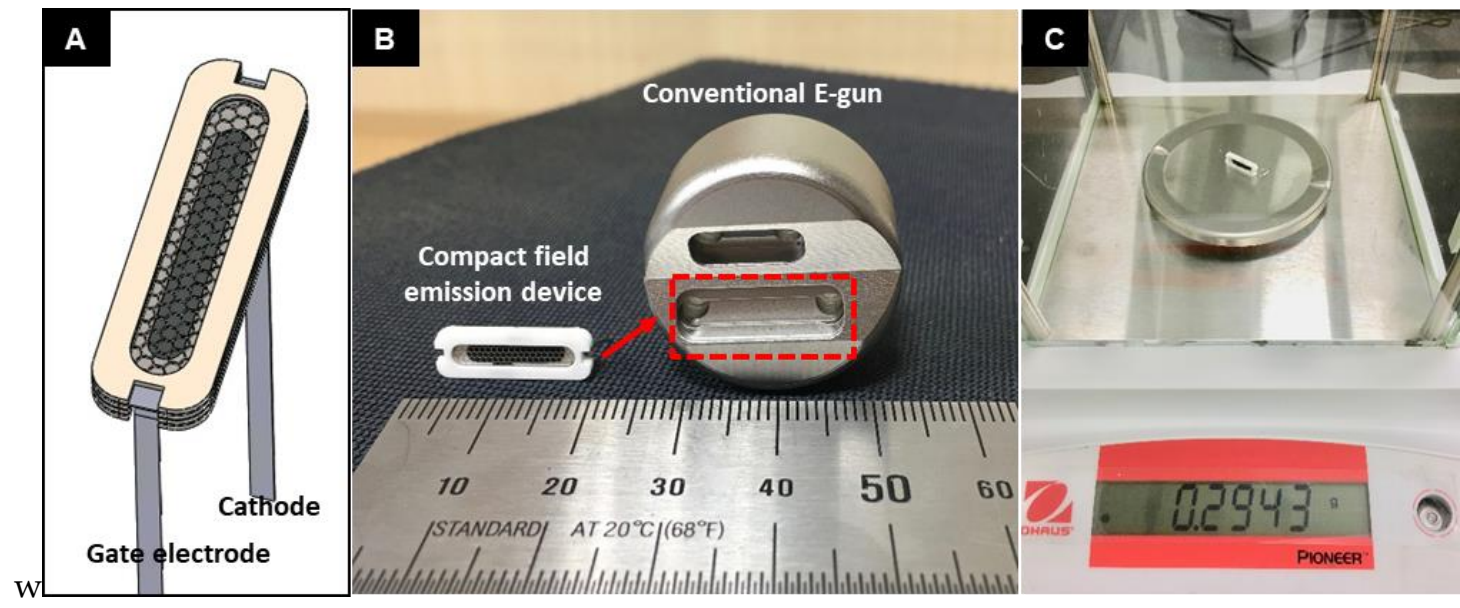

Figure 2. (A) 3D design of compact field emission device embedded with directly grown CNT on metal substrate; (B) photo image of compact field emission device and conventional dual type electron gun after removing filament emitter; (C) photo image of 0.2943 gram-weight of compact field emission device.

\section{Results and Discussion}

\subsection{CNT Emitter for Compact Field Emission Device}

Figure 3A,B shows SEM images of CNTs on a metal substrate, taken at 5 and $1 \mu \mathrm{m}$ scale, respectively. It is evident that the forest of $\mathrm{CNTs}$ was densely grown over a large area on the substrate. This is proof that $\mathrm{Ni}$ and Fe compounds act as catalysts in the growth of CNTs on the metal alloy substrate. The presence of these catalysts has the exclusion of an extra process required to form a catalyst layer. The CNTs exhibited a spaghetti-like orientation, as shown in Figure 3C. The lack of vertical alignment requires further investigation but appears to be due to the combined effect of substrate roughness and low plasma intensity [23]. Although the dense forest of CNTs was achieved on the metal alloy substrate, the crowding effect was not strong enough to align the CNTs vertically, as is the case for CNTs grown on Si substrates [27]. Since the CNTs were not vertically oriented, it was difficult to measure their exact average length but we have estimated it to be between 20 and 
$30 \mu \mathrm{m}$. Figure 3D shows the TEM image of a CNT tip, where the presence of Ni on the tip signifies tip growth of the CNT. Figure 3E shows that the synthesized multi-walled CNTs (MWCNTs) have a layer thickness of $80 \mathrm{~nm}$ with a highly crystalline surface.

\subsection{Raman Spectrum of PECVD Sythensized CNT}

The Raman spectrum of synthesized CNT is shown in Figure 3F. Typically, the first order G band (corresponding to the degree of nanotubes graphitization) and $\mathrm{D}$ band (corresponding to the degree of nanotubes structure disorder) for MWCNT are respectively $\sim 1580$ and $\sim 1350 \mathrm{~cm}^{-1}[10,28]$. In this Raman spectrum, obtained G and D bands are respectively 1582.8 and $1357.6 \mathrm{~cm}^{-1}$, confirming the presence of MWCNTs possessing the intensity ratio ID/IG of 0.81 . This is consistent with results obtained for diamond-like carbon (DLC) doped with $\mathrm{ZnO}$ [29]. Our results support less disorder in the synthesized CNTs, which is quite anomalous for CNTs synthesized by the PECVD process [30]. Generally, the ID/IG ratio of the PECVD process is greater than 1, but as a result of high temperature $\left(900^{\circ} \mathrm{C}\right)$ synthesis of the CNTs, the degree of disorder decreased significantly as in Chemical Vapor Deposition (CVD) [31]. This preserved the crystallinity of the graphitic surface of the MWCNTs.

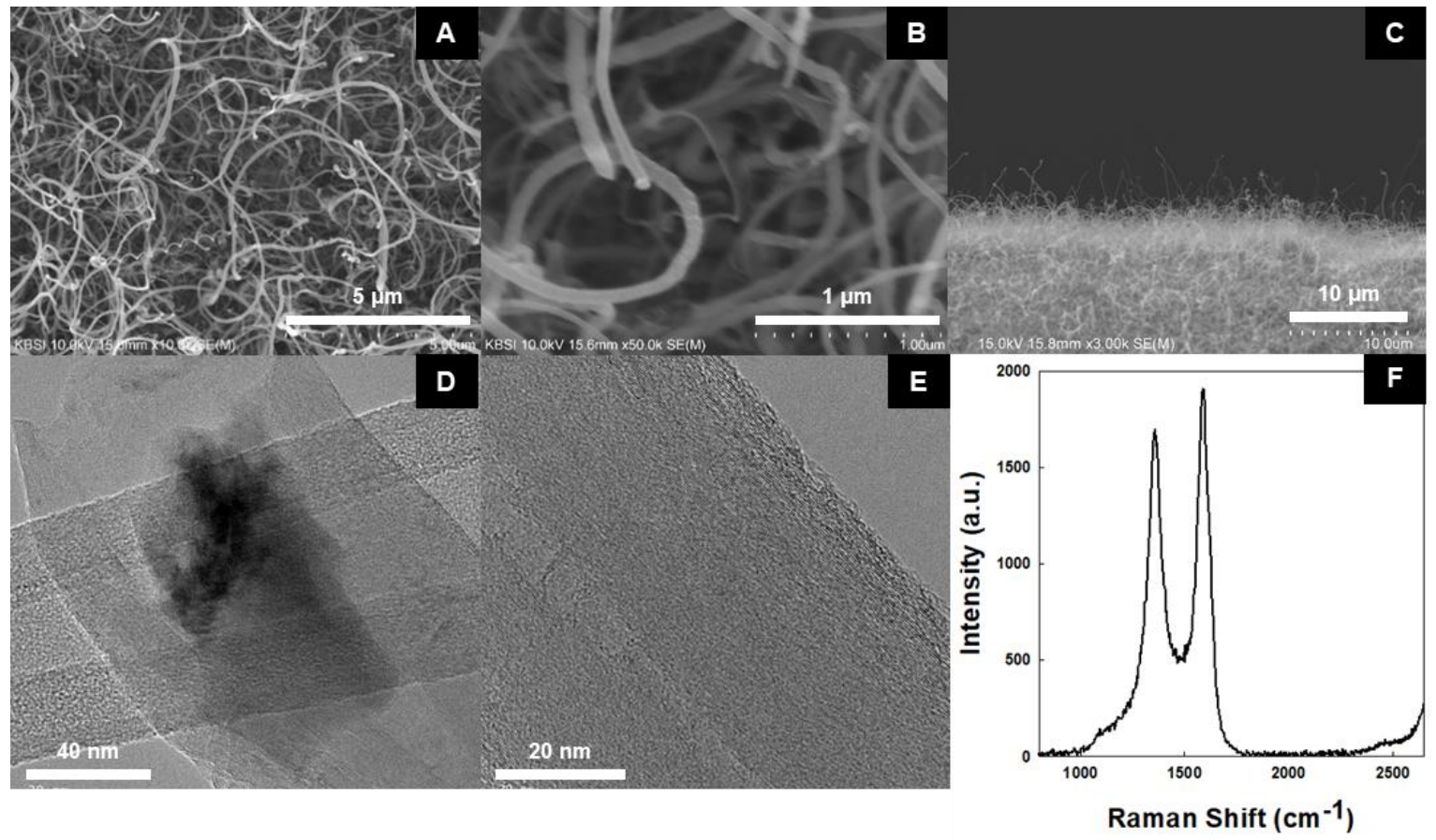

Figure 3. (A,B) SEM images of CNTs grown on metal substrate synthesized by PECVD; (C) lateral SEM Image (D) and (E) TEM image of CNTs; (F) Raman spectrum of CNTs.

\subsection{Field Emission Measurment Using Compact Field Emission Device}

To measure the FE properties of the CNTs, the electrical aging process was performed for 50 repeatable FE cycles. The electrical aging process was carried out to produce stable FE [32]. Figure 4A illustrates the current density vs. electric field characteristic of the CNT emitters after the electrical aging process. Figure $4 \mathrm{~B}$ shows the semi-log plot of the cathode current density, showing turn-on $\left(1 \mu \mathrm{A} / \mathrm{cm}^{2}\right)$ and threshold $\left(1 \mathrm{~mA} / \mathrm{cm}^{2}\right)$ fields of 2.84 and $4.05 \mathrm{~V} / \mu \mathrm{m}$, respectively. The peak value of the current density was $7 \mathrm{~mA} / \mathrm{cm}^{2}$ at the electric field of $5.24 \mathrm{~V} / \mu \mathrm{m}$ for the cathode current. The peak value for the anode and the gate currents were 5.77 and $1.23 \mathrm{~mA} / \mathrm{cm}^{2}$, respectively. The leakage current of the gate electrode was calculated to be $17.7 \%$. Figure $4 \mathrm{C}$ shows the Folwer-Nordheim (FN) plot of the FE of the fabricated CNTs. 
To obtain the field enhancement factor $\beta$, (i.e., the ratio of the local electric field around the emitter tips and the applied macroscopic electric field) the following equation (FN plot) was used to fit the experimental data [33].

$$
\ln \left(\frac{\mathrm{J}}{\mathrm{E}^{2}}\right)=\mathrm{a}-\frac{6.8 \times 10^{3} \phi^{3 / 2}}{\beta \mathrm{E}} .
$$

Here, $\mathrm{J}, \mathrm{E}$, and $\phi$, are respectively the cathode current density $\left(\mathrm{mA} / \mathrm{cm}^{2}\right)$, electric field between the gate and cathode $(\mathrm{V} / \mu \mathrm{m})$, and the CNT work function $(\mathrm{eV})$ [34]. The work function of the CNTs was assumed to be $4.7 \mathrm{eV}$ [35], whereas their field enhancement factor was calculated to be 2838 at a high electric field (highlighted in the figure by the top solid green line) and 1205 at a low electric field (highlighted in the figure by the bottom solid red line). Figure $4 \mathrm{C}$ illustrates the stability of the CNT emitter for $420 \mathrm{~min}$. The initial current density was $6.7 \mathrm{~mA} / \mathrm{cm}^{2}$ at the electric field of $5.2 \mathrm{~V} / \mu \mathrm{m}$. During $420 \mathrm{~min}$, maximum current density was $7.06 \mathrm{~mA} / \mathrm{cm}^{2}$, and minimum current density was $6.53 \mathrm{~mA} / \mathrm{cm}^{2}$. This result indicates high stability of the CNT emitters.
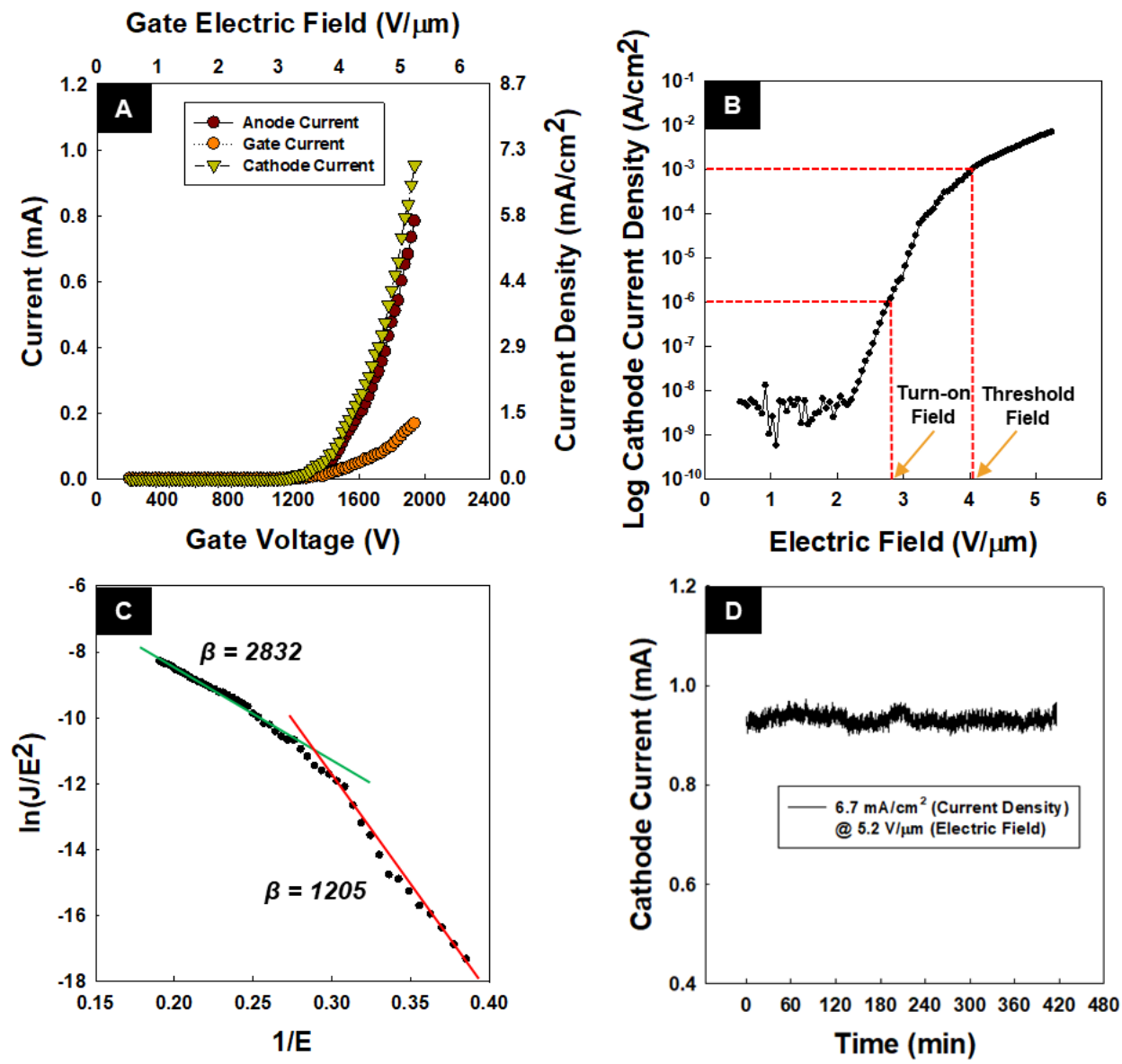

Figure 4. (A) I-V curve; (B) semi log plot; (C) the FN plot; (D) stability of CNT emitter.

\subsection{X-ray Image Acqusition Using Compact Field Emission Device Embedded in Conventional Electron Gun}

Figure 5a,b shows the optical image and X-ray generated image of the integrated circuit by an Open-type X-ray system using CNT field emitters. The X-ray image was taken at an anode accelerating voltage of $55 \mathrm{kV}$ with anode current of $0.5 \mathrm{~mA}$ by being exposed for $100 \mathrm{~ms}$. Comparing the scale bars of the optical image and the X-ray image, the high-resolution image under $100 \mu \mathrm{m}$ was obtained. 

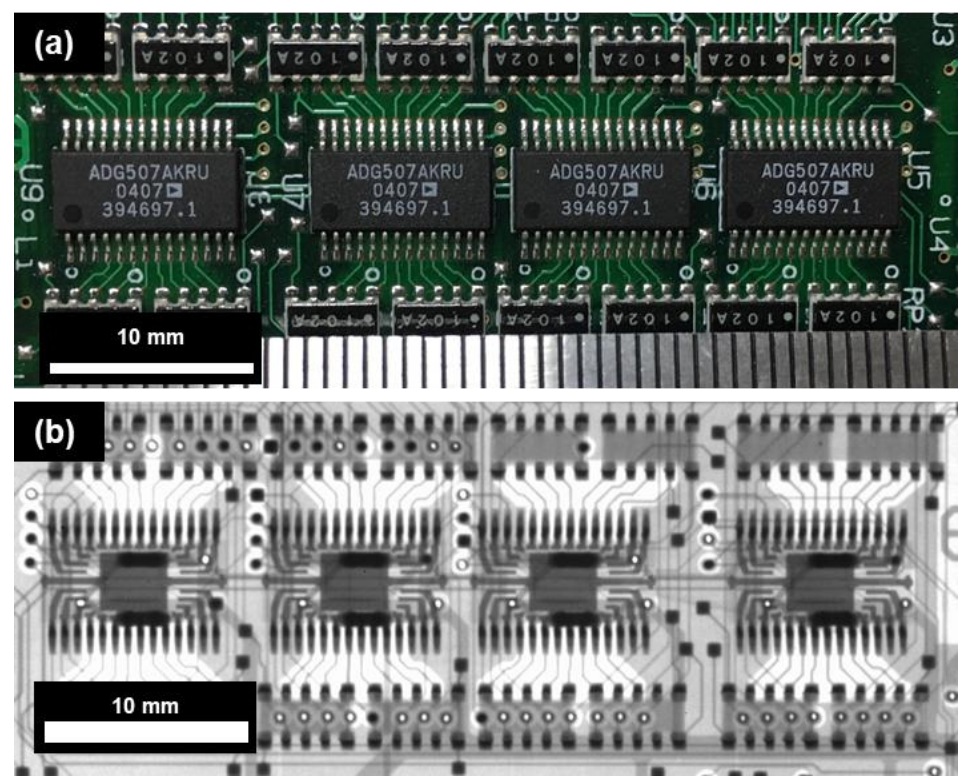

Figure 5. (a) The optical image and (b) X-ray image of integrated circuit taken at $55 \mathrm{kV} / 0.5 \mathrm{~mA}$.

\section{Conclusions}

A cost-effective and simple process to synthesize CNTs on a metal alloy substrate has been demonstrated. Through an optimized PECVD process, a highly stable and high-performance CNT emitter was synthesized. The CNT emitter was custom assembled into a compact and light-weight FE device which is capable of replacing the thermionic emitters in conventional electron guns. The compactly assembled electron gun yielded an enhanced and stable electron FE, which was able to produce a high-resolution X-ray image. Furthermore, this research focuses on improving the FE properties, such as the extraction of more currents at low electric field in the triode configuration and the use of CNT-based electron field emitters for multi X-ray source devices. Applications for the emitter presented herein are limitless, extending to CT scans and tomosynthesis. The target is to replace analog, thermionic filament-based X-ray machines in a sustainable and economic manner.

Author Contributions: J.R. conceived and designed the experiments. S.P., A.P.G. and J.J. performed the CNT growing process; S.J.Y., M.M. and J.S.A. analyzed the FE data of electron gun. S.H.P. and S.H.K. obtained the X-ray image from the open-type X-ray system. J.H.S. analyzed the X-ray imaging process. S.P. and A.P.G. wrote the paper.

Acknowledgments: This research is supported by the Bio \& Medical Technology Development Program of the National Research Foundation (NRF) funded by the Ministry of Science \& ICT (NRF-2018M3A9E9024942) and Ministry of SMEs and Startups (1425112479) and Seoul Metropolitan Bio Medical Project (TB170131).

Conflicts of Interest: The authors declare no conflict of interest.

\section{References}

1. De Heer, W.A.; Chatelain, A.; Ugarte, D. A carbon nanotube field-emission electron source. Science 1995, 270, 1179-1180. [CrossRef]

2. Liu, Z.; Yang, G.; Lee, Y.Z.; Bordelon, D.; Lu, J.; Zhou, O. Carbon nanotube based microfocus field emission X-ray source for microcomputed tomography. Appl. Phys. Lett. 2006, 89. [CrossRef]

3. Read, M.; Kremer, M.; Schwarz, W.; Lennhoff, J.; Carnahan, D.; Ren, Z. Carbon nanotube-based cathodes for microwave tubes. IEEE Int. Conf. Plasma Sci. 2001, 2, 1026-1028. [CrossRef]

4. Wang, Q.; Wang, J.; Di, Y.; Lei, W.; Zhang, X.; Zhu, Z. Shadow mask field emission display with carbon nanotubes emitters. Diam. Relat. Mater. 2008, 17, 217-222. [CrossRef]

5. Meyyappan, M.; Delzeit, L.; Cassell, A.; Hash, D. Carbon nanotube growth by PECVD—A review. Plasma Sources Sci. Technol. 2003, 12, 205-216. [CrossRef] 
6. Li, D.; Cheng, Y.; Wang, Y.; Zhang, H.; Dong, C.; Li, D. Improved field emission properties of carbon nanotubes grown on stainless steel substrate and its application in ionization gauge. Appl. Surf. Sci. 2016, 365, 10-18. [CrossRef]

7. Zhu, W.; Zhang, Y.; Xu, N.; Tan, Y.; Zhan, R. Epitaxial growth of multiwall carbon nanotube from stainless steel substrate and effect on electrical conduction and field emission. Nanotechnology 2017, 28, 305704. [CrossRef] [PubMed]

8. Hashempour, M.; Vicenzo, A.; Zhao, F.; Bestetti, M. Direct growth of MWCNTs on 316 stainless steel by chemical vapor deposition: Effect of surface nano-features on CNT growth and structure. Carbon N. Y. 2013, 63, 330-347. [CrossRef]

9. Ryu, J.H.; Kim, W.S.; Lee, S.H.; Eom, Y.J.; Park, H.K.; Park, K.C. Vertically Aligned Carbon Nanotube Emitter on Metal Foil for Medical X-ray Imaging. J. Nanosci. Nanotechnol. 2013, 13, 7100-7103. [CrossRef] [PubMed]

10. Yuan, X.; Cole, M.; Zhang, Y.; Wu, J.; Milne, W.; Yan, Y. Parametrically Optimized Carbon Nanotube-Coated Cold Cathode Spindt Arrays. Nanomaterials 2017, 7, 13. [CrossRef] [PubMed]

11. Li, X.; Baker-Fales, M.; Almkhelfe, H.; Gaede, N.R.; Harris, T.S.; Amama, P.B. Rational Modification of a Metallic Substrate for CVD Growth of Carbon Nanotubes. Sci. Rep. 2018, 8, 4349. [CrossRef] [PubMed]

12. Gupta, A.P.; Park, S.; Yeo, S.J.; Jung, J.; Cho, C.; Paik, S.H.; Park, H.; Cho, Y.C.; Kim, S.H.; Shin, J.H.; et al. Direct synthesis of carbon nanotube field emitters on metal substrate for open-type X-ray source in medical imaging. Materials 2017, 10, 878. [CrossRef] [PubMed]

13. Puett, C.; Inscoe, C.; Hartman, A.; Calliste, J.; Franceschi, D.K.; Lu, J.; Zhou, O.; Lee, Y.Z. An update on carbon nanotube-enabled X-ray sources for biomedical imaging. Wiley Interdiscip. Rev. Nanomed. Nanobiotechnol. 2017, 1-11. [CrossRef] [PubMed]

14. Basu, A.; Swanwick, M.E.; Fomani, A.A.; Velásquez-García, L.F. A portable X-ray source with a nanostructured Pt-coated silicon field emission cathode for absorption imaging of low-Z materials. J. Phys. D Appl. Phys. 2015, 48, 225501. [CrossRef]

15. Li, Y.; Zhang, Z.; Zhang, G.; Zhao, L.; Deng, S.; Xu, N.; Chen, J. Optimizing the field emission properties of $\mathrm{ZnO}$ nanowire arrays by precisely tuning the population density and application in large-area gated field emitter arrays. ACS Appl. Mater. Interfaces 2017, 9, 3911-3921. [CrossRef] [PubMed]

16. Zhu, N.; Chen, J. Design, fabrication and characterization of molybdenum field emitter arrays (Mo-FEAs). Micromachines 2017, 8, 162. [CrossRef]

17. Urban, F.; Passacantando, M.; Giubileo, F.; Iemmo, L.; Di Bartolomeo, A. Transport and Field Emission Properties of MoS2 Bilayers. Nanomaterials 2018, 8, 151. [CrossRef] [PubMed]

18. Sankaran, K.J.; Kunuku, S.; Leou, K.-C.; Tai, N.-H.; Lin, I.-N. Enhancement of the Electron Field Emission Properties of Ultrananocrystalline Diamond Films via Hydrogen Post-Treatment. ACS Appl. Mater. Interfaces 2014, 6, 14543-14551. [CrossRef] [PubMed]

19. Di Bartolomeo, A.; Giubileo, F.; Iemmo, L.; Romeo, F.; Russo, S.; Unal, S.; Passacantando, M.; Grossi, V.; Cucolo, A.M. Leakage and field emission in side-gate graphene field effect transistors. Appl. Phys. Lett. 2016, 109. [CrossRef]

20. Puett, C.; Calliste, J.; Wu, G.; Inscoe, C.R.; Lee, Y.Z.; Zhou, O.; Lu, J. Contrast enhanced imaging with a stationary digital breast tomosynthesis system. SPIE Med. Imaging 2017, 10132, 1013225. [CrossRef]

21. Walker, B.J.; Radtke, J.; Chen, G.H.; Eliceiri, K.W.; Mackie, T.R. A beam optics study of a modular multi-source X-ray tube for novel computed tomography applications. Nucl. Instrum. Methods Phys. Res. A 2017, 868, 1-9. [CrossRef]

22. Schreiner, R.; Langer, C.; Prommesberger, C.; Dams, F. Compact and Energy-Efficient Field Emission Cathodes for Sensor Applications. Adv. Mater. Res. 2014, 1024, 372-375. [CrossRef]

23. Park, D.; Kim, Y.H.; Lee, J.K.E.E. Pretreatment of stainless steel substrate surface for the growth of carbon nanotubes by PECVD. J. Mater. Sci. 2003, 8, 4933-4939. [CrossRef]

24. Wang, S.; Wang, P.; Zhou, O. Effects of NH3plasma pretreatment on the growth of carbon nanotubes. Diam. Relat. Mater. 2006, 15, 361-364. [CrossRef]

25. Sun, Y.; Shin, D.H.; Yun, K.N.; Hwang, Y.M.; Song, Y.; Leti, G.; Jeon, S.G.; Kim, J.I.; Saito, Y.; Lee, C.J. Field emission behavior of carbon nanotube field emitters after high temperature thermal annealing. AIP Adv. 2014, 4. [CrossRef]

26. Ren, Z.F.; Lan, Y.; Wang, Y. Aligned Carbon Nanotubes; Avouris, P., Bhusan, B., Bimberg, D., Klitzing, K.V., Sakaki, H., Wiesendenger, R., Eds.; Springer: Berlin, Germany, 2013; pp. 73-74. ISBN 978-3-642-30490-3. 
27. Di Bartolomeo, A.; Scarfato, A.; Giubileo, F.; Bobba, F.; Biasiucci, M.; Cucolo, A.M.; Santucci, S.; Passacantando, M. A local field emission study of partially aligned carbon-nanotubes by atomic force microscope probe. Carbon N. Y. 2007, 45, 2957-2971. [CrossRef]

28. Kennedy, J.; Fang, F.; Futter, J.; Leveneur, J.; Murmu, P.P.; Panin, G.N.; Kang, T.W.; Manikandan, E. Synthesis and enhanced field emission of zinc oxide incorporated carbon nanotubes. Diam. Relat. Mater. 2017, 71, 79-84. [CrossRef]

29. Manikandan, E.; Kavitha, G.; Kennedy, J. Epitaxial zinc oxide, graphene oxide composite thin-films by laser technique for micro-Raman and enhanced field emission study. Ceram. Int. 2014, 40, 16065-16070. [CrossRef]

30. Bokobza, L.; Zhang, J. Raman spectroscopic characterization of multiwall carbon nanotubes and of composites. Express Polym. Lett. 2012, 6, 601-608. [CrossRef]

31. Gohier, A.; Minea, T.M.; Point, S.; Mevellec, J.Y.; Jimenez, J.; Djouadi, M.A.; Granier, A. Early stages of the carbon nanotube growth by low pressure CVD and PE-CVD. Diam. Relat. Mater. 2009, 18, 61-65. [CrossRef]

32. Ryu, J.H.; Kim, K.S.; Lee, C.S.; Jang, J.; Park, K.C. Effect of electrical aging on field emission from carbon nanotube field emitter arrays. J. Vac. Sci. Technol. B Microelectron. Nanom. Struct. 2008, 26, 856. [CrossRef]

33. Li, Y.; Sun, Y.; Yeow, J.T.W. Nanotube field electron emission: Principles, development, and applications. Nanotechnology 2015, 26, 242001. [CrossRef] [PubMed]

34. Bocharov, G.; Eletskii, A. Theory of Carbon Nanotube (CNT)-Based Electron Field Emitters. Nanomaterials 2013, 3, 393-442. [CrossRef] [PubMed]

35. Su, W.S.; Leung, T.C.; Chan, C.T. Work function of single-walled and multiwalled carbon nanotubes: First-principles study. Phys. Rev. B-Condens. Matter Mater. Phys. 2007, 76, 2-9. [CrossRef]

(C) 2018 by the authors. Licensee MDPI, Basel, Switzerland. This article is an open access article distributed under the terms and conditions of the Creative Commons Attribution (CC BY) license (http:// creativecommons.org/licenses/by/4.0/). 